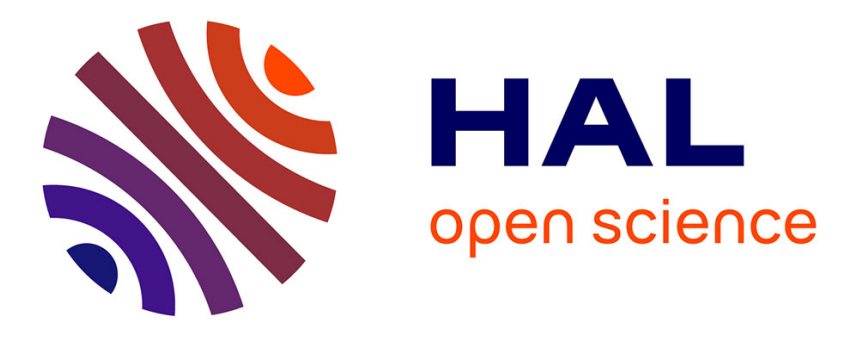

\title{
Dentists' perspectives on barriers to providing oral health care in French psychiatric hospitals with on-site dental clinics
}

\author{
Antoine Couatarmanach, William Sherlaw, Pierre-Marie Prigent, Cyrille \\ Harpet, Valérie Bertaud
}

\section{To cite this version:}

Antoine Couatarmanach, William Sherlaw, Pierre-Marie Prigent, Cyrille Harpet, Valérie Bertaud. Dentists' perspectives on barriers to providing oral health care in French psychiatric hospitals with on-site dental clinics. Community Dentistry and Oral Epidemiology, 2020, 48 (4), pp.296-301. 10.1111/cdoe.12532 . hal-02532849

HAL Id: hal-02532849

https://hal-univ-rennes1.archives-ouvertes.fr/hal-02532849

Submitted on 27 May 2020

HAL is a multi-disciplinary open access archive for the deposit and dissemination of scientific research documents, whether they are published or not. The documents may come from teaching and research institutions in France or abroad, or from public or private research centers.
L'archive ouverte pluridisciplinaire HAL, est destinée au dépôt et à la diffusion de documents scientifiques de niveau recherche, publiés ou non, émanant des établissements d'enseignement et de recherche français ou étrangers, des laboratoires publics ou privés. 
Dentists' perspectives on barriers to providing oral health care in French psychiatric hospitals with on-site dental clinics.

Antoine Couatarmanach, DDS, Faculty of dentistry, University of Rennes, UMR 6051, CHU Rennes,

William Sherlaw, PhD, Ecole des Hautes Etudes en Santé Publique (EHESP), UMR 6051, Pierre-Marie Prigent, DDS, Rennes,

Cyrille Harpet, PhD, Ecole des Hautes Etudes en Santé Publique (EHESP), UMR 6051, Valérie Bertaud, DDS, PhD, Faculty of dentistry, University of Rennes, LTSI, CHU Rennes.

Authors contribution statement:

A.C., WS, $\mathrm{CH}$ and VB designed the study, A.C. and P.M.P. conducted the interviews, all the authors contributed to the analysis, A.C. took the lead in writing the manuscript, and all the authors provided critical feedback and helped shape the manuscript. 


\section{Abstract}

Objectives: Psychiatric inpatients suffer from poorer oral health than the general population, and difficulties in accessing necessary dental treatment remain even when a dedicated dental service is available within the psychiatric hospital. The aim of this study was to identify barriers to access dental care from the point of view of dentists working within French psychiatric hospitals.

Methods: The relatively small number of dentists working in psychiatric hospitals necessitated a qualitative approach. Semi-structured interviews were conducted, recorded, transcribed, and coded in a conventional content analysis approach.

Results: Eight interviews were conducted. Six of the dentists interviewed were men, two were women. Three of them worked full-time in a psychiatric facility, while the other five worked partly in the hospital and partly in private practice. The average duration for interviews was 54 minutes (minimum $24 \mathrm{~min}$, maximum $89 \mathrm{~min}$ ). The interviews highlighted three dimensions of barriers to access to dental care. The first dimension was directly related to the patient. This may be linked to the patient's psychiatric disorder but not necessarily. This also encompasses refusal of care. A second dimension regrouped events related to the organization of the hospital (locally), such as communication issues between staff members within the dental office, and with other staff members from the psychiatric ward. A third dimension included difficulties related to the overall organization of the health care system, including financial issues and deinstitutionalization.

Conclusions: In-site dental consultations appear as an interesting tool to enhance access to oral care for psychiatric inpatients. However, difficulties remain from the dentists' perspective. 


\section{Introduction}

In the past ten years, several reviews and meta-analyses have confirmed that people with mental health disorders suffer from poorer oral health than the general population ${ }^{1-3}$. Many causes have been identified, including the effects of psychiatric medications, a lack of dental hygiene, high smoking rates, unhealthy diets and poorer access to oral health care ${ }^{4}$. In turn, oral diseases can have deleterious consequences on both the physical and the mental health of these patients ${ }^{5}$. This situation puts people with mental health disorders in the paradoxical position of being "objectively" in greater need for oral health care but less able to access it than the general population ${ }^{6}$.

This situation has been highlighted for people receiving psychiatric care in the community (out-patients) ${ }^{7,8}$ as well as, and even more so, for people hospitalised in psychiatric facilities (psychiatric in-patients) ${ }^{9-18}$. Dedicated dental clinics inside psychiatric hospitals might be considered as a useful tool to enhance access for psychiatric inpatients, and some authors have called for such services ${ }^{19}$. Indeed, three epidemiological studies investigating the dental status of psychiatric inpatients reported that the hospital where the study was conducted did benefit from such in-site dental clinics ${ }^{10,12,14}$. Despite evidence showing that the availability of dental clinic within psychiatric institutions facilitates hospitalized patients’ oral health ${ }^{20,21}$, the evidence indicates that barriers persist in these situations.

Recent studies investigating barriers to oral care for people suffering from mental health disorders, based on literature review ${ }^{22}$ and qualitative inquiries, have focused on the perceptions of either dental professionals ${ }^{23}$ and mental health professionals ${ }^{24}$. However, no studies have focused on the barriers faced by psychiatric in-patients. Considering the unique environment psychiatric institutions constitute, there is a need for research focused on those specific situations.

Despite an ongoing deinstitutionalization process and strong regional disparities, the delivery of psychiatric care remains largely hospital-based in France ${ }^{25-27}$. Even if no systematic data are available, previous studies indicates that in-site dental clinics do exist in this country ${ }^{8,10}$. The aim of this study is to identify, from the perspective of dentists working in psychiatric hospitals in France, the barriers that still remain for oral health, even when an in-site dental clinic is available. 


\section{Methods}

This study was designed as a qualitative inquiry based on semi-structured interviews with dentists working within psychiatric hospitals in France. The protocol was validated from the ethical point of view by University Hospital ethics committee in Rennes (notice $n^{\circ} 19.01$ ).

In order to recruit participants, psychiatric hospitals were first contacted by telephone to establish whether dental consultations were available within the institution, starting with the closest from the researchers' work place, and then widening the search progressively to other hospitals elsewhere in France. When the hospital reported the existence of an in-site dental clinic, the dentist was identified and contacted by mail or telephone in order to explain him/her the goals and methods of this study. When he/she agreed to participate, an appointment was settled for a face-to-face interview. Before starting the interview, a consent form was delivered, informing the participant that his/her discourse would remain anonymous and that he/she would be able to withdraw from the study.

Semi-structured interviews were conducted, starting systematically with a question about their previous professional trajectory, and what led them to work in a psychiatric hospital. From this common starting point, participants were then asked about the difficulties they were facing delivering dental care in those facilities. Considering that the objective of the interviews was to highlight dentist's perceptions, and facilitate the emergence of unknown issues, participants were encouraged to provide accounts of their experiences and elaborate on the problematic issue ${ }^{28}$.

Interviews were fully transcribed with Sonal ${ }^{\circledR}$ (V 2.1.41). Given the lack of previous knowledge on this particular matter, a conventional content analysis approach was chosen in order to highlight unrevealed themes ${ }^{29}$. The coding process was performed manually and independently by two researchers in order to limit personal bias in the interpretation of dentist's responses. Codes were then discussed and organised in themes in an inductive way. Interviews were coded consecutively, when they were available, allowing the investigator to compare them during the process of data collection. Saturation was considered to have been reached when no new themes could be extracted from the last interview. At this step, multiple readings of the interviews were performed in order to verify key themes and identify recurrences and differences among the interviews. Collective discussions finally allowed to confirm key themes and regroup them into broader dimensions. 


\section{Results}

A total of 15 psychiatric hospitals were contacted. Five didn’t benefit from on-site dental clinics. Among the 10 dentists that were identified, 2 refused to participate arguing the lack of time. Eight interviews were finally conducted between January 2018 and March 2019. The average duration of the interviews was 54 minutes (minimum 24 min, maximum $89 \mathrm{~min}$ ). Characteristic features of the interviewed dentists are summarized in table 1.

The content analysis of the interviews permitted to highlight three dimensions of barriers to oral health care perceived by the dentists working in psychiatric hospitals: an individual dimension related to the patient situation and the dentists-patient relationship; a "local organization" dimension related to interprofessional relationships; a systemic dimension related to the organization of the health care system.

\section{Individual dimension}

Themes were classified as an individual matter when they were related, in the dentist's perception, with the personal and medical situation of the hospitalised patient. Every dentist who was interviewed identified mental disorder itself as a barrier to dental care. Despite the huge diversity of pathologies (from schizophrenia to severe depression) affecting the patients, dentists described a general lack of hygiene. Pharmacological treatments were also generally pointed out as a negative factor, especially for their impact on salivation. Psychoactive substance use was also seen as a major and frequent issue for its consequences on oral health. A recurrent consequence of mental disorder identified by the dentists was its impact on the involvement in the dental care process they could expect from the patients. This lack of involvement can express itself in patient refusal:

We can see people that refuse dental treatment, they come but you can't touch them, and they run away... and you can't treat them against their will.

There are 30 to $40 \%$ of the patients who refuse dental care, they say "No, I'm OK like that, don't touch my mouth", and the nurse call us to say that he's not going to come to the appointment, and we're not going to force him to come.

The relationship between mental disorder and the patient's social situation was also regularly pointed out, to explain the issue of involvement in dental care: 
We can see patients who experience precarious situations, who get here [in the hospital] because of this precariousness, or because their mental condition makes them face precarious situations, and so dental care, body care, are not really considered.

This lack of involvement was also linked, from the dentists' perspective, with the relatively low importance of aesthetics for some patients:

One of his front teeth was took off, I don't know when, not so long ago. He doesn't seem to care, he's 35... He’s missing a lateral [upper lateral incisor] but well...

However, this low involvement was not seen as systematic. Many patients were described as really looking after dental care:

I have a proportion of patients who are really concerned about their dental care, really concerned.

Mental disorders were also seen as impacting on the dental care relationship. Psychiatric inpatients were described as being in need for specific approaches. Dentist behaviour and time were recurrently identified as the main issues in order to create a favourable care relationship:

With general population, it's the patient who have to adapt: "a little bit on the left, turn the head". In psychiatry, it's the opposite, it's for us, the dentist, to adapt.

Sometimes the talking can last for half an hour, for one hour... Well it depends, in order to really motivate them, because it might not be the proper time for starting treatments, but it's still a part of the story.

Questions were asked about the need for violence management, but this wasn't described as a real issue by the interviewed dentists:

Well they have difficulties and sometimes they can have violent behaviours, but when they are in this kind of states, they usually don't come here. If they do come here, I know what I can and cannot do and so I never got molested.

Finally, mental disorder was sometimes described, on the contrary, as a factor that can facilitate the dental care relationship. This had mainly to do with the fact that patients with mental disorders wouldn't hide their reactions and feelings:

Every patient is scared, but here [in the psychiatric hospital], I have never faced faintness, never ever. Because the patient expresses it when he is not feeling well. He says it. 
He's going to agitated, to refuse... Well, I'll know it. Whereas in private practice, some patients will hold their feelings in, interiorise, until they faint and fall down.

\section{“Local organization” dimension}

The "local organisation" dimension regrouped themes pertaining to the nature of the relations between the dentist and his/her environment in the institution. These relations, and how they were managed and carried out, appeared to be an important matter of interest for the interviewed dentists. The related issues were usually mentioned before any questions were asked about them. First of all, the quality of relationships among the different members of the dentistry unit were seen as an important enabler for the delivery of dental care. Beyond the need for assistance expressed by dentists for several tasks (as appointments management, sterilization, ordering materials), the importance of good relationships with dental assistants was specifically highlighted for their ability to perform multiple functions and their experience dealing with mental health issues:

They are able to take care of radiology, gynaecology... I used to have a radiology assistant for dental assistant.

As former psychiatric nurse, my assistant has a deep knowledge of psychiatric disorders and she even knows personally some of the patients that have been hospitalised for a long time.

Relationships with other professionals from the psychiatric ward were also considered as a major matter of interest. The nature and efficacy of communication with nurses, general practitioners and psychiatrists varied according to the hospital involved, and so it was perceived as a barrier where this communication was difficult, and as an enabler in hospitals where it was easy. The main contact for dentists appeared to be the general practitioner:

Relationships are principally mediated by the general practitioner, he's the one who address the patients.

General practitioners have the kindness to coordinate for me, and to tell me when there's a problem. 
Interactions with the nurses in psychiatrics units were also described as an important feature for the organization of appointments, as well as for preparing the patients before dentist's appointment, or the improvement of daily dental care. This relation was frequently described as non-efficient:

The main barrier is the motivation of nursing teams. It varies a lot depending on the unit.

Relations with the psychiatrist were usually described as poor, if not inexistent. All such limitations in the relations dentists can have with other staff members were seen as a symptom of the specialized orientation of the psychiatric hospital, relegating the somatic dimension:

Here we are in a psychiatric hospital where... I mean, in fact, somatic issues do not have a proper place here.

Limitations in inter-professional relationships were perceived as having multiple consequences, particularly for the organisation of appointments. For example, there was a consensus on the need for regular dental check-up visits for psychiatric inpatients, but those were described as difficult to set up:

I fight for this all the time but I have to admit that I'll never get it. I used to hope we could organise a regular follow-up of the patients, but that's some something we'll never get.

The "local organisation" dimension also included technical issues related to the quality of dental office equipment, as well as access to specific treatment facilities such as nitrous oxide sedation and general anaesthesia. All of the interviewed dentists were satisfied with their material organisation for conventional treatment, and several were able to perform treatment under nitrous oxide sedation. On the other hand, access to general anaesthesia was indicated as a recurrent issue, highly dependent on the medical offer in the region, since none of the psychiatric hospitals were equipped to perform general anaesthesia within the facility:

We don't perform treatments under general anaesthesia here. There's a huge need for it, but it's unmet. Sometimes, the general practitioner, rarely, can react and send the patient to [university hospital] which is $100 \mathrm{~km}$ away. 


\section{Systemic dimension}

The systemic dimension comprised themes implicating the whole health system. The question of the training and professional development of the different professionals involved was systematically addressed, and appeared as a debatable topic. Training of dentists on the specific issues of psychiatry was seen as an important enabler by some dentists, but others considered it to be irrelevant, the most important thing being tacit knowledge that could be acquired only by experience:

It's not a matter of training, it's a matter of stance... I don't know... The question is how you interact with the patients.

It is noteworthy that only one of the eight dentists who were interviewed reported that he had benefitted from a special course on mental health issues.

There was more consensus about the need for training and professional development of nurses in oral health issues. A recurrent enabler to be described was the training of nurses (in psychiatric wards) who could act as correspondents for oral care in the units. Some dentists mentioned its existence in other institutions and it was perceived as something that needed to be developed in psychiatric hospitals:

The organization is more coherent, as there's an identified person in every unit in charge of the oral health issue. This person, after time spent observing dental appointments, seeing what's going on, can communicate with the other staff members in the unit.

Another important barrier identified by the participants was the tendency, in psychiatric hospitals, to shorten the length of hospitalization. It was perceived to be the outcome of the general process of de-institutionalization, leaving mental care of patients to either the community or the housing facilities separated from the hospital. All of the interviewed dentists expressed difficulties arising from the increased turn-over of patients in the hospital; it was seen as a threat that could compromise dental care:

The main problem is that the patients leave the hospital more and more quickly nowadays. They used to stay longer, now they leave as soon as possible, and it's not easy to follow up... 
Finally, financial issues were also highlighted, especially for their impact on recruitment. Indeed, the remuneration for working in psychiatric hospitals, based on fixed salary scales, was unanimously described as lower than in private practice. In a context of declining demographics of dentists, the interviewed dentists who were close to retirement expressed the fear that it might be difficult to find someone to replace them. This was then perceived as a potential barrier. However, when asked about their motivation for working in psychiatric hospitals, participants did not mention the economic incentive. On the contrary, they described their choice as the consequence of a social mandate:

I found myself a bit morally constrained to stay here, because I think that's a population who really needs to be taking care of, and who faces real difficulties to find dental care solutions.

I also work in a private practice and I'm really proud of that. But I'm always keeping in mind the sense of state. Always in the service of the state.

\section{Discussion}

This study highlights the barriers dentists working in psychiatric hospitals in France are facing in delivering dental care. First, barriers were identified as linked to the individual situation of the patients. Such barriers have been identified for a long time and strategies have been proposed to overcome these ${ }^{30}$. In fact, it appears from the interviews that dedicated dental clinics inside psychiatric hospitals help to create the conditions to reduce such individual barriers.

Organisation-related barriers were described as being much more resistant by the participants. The lack of communication between dental professionals and psychiatric teams has also been previously identified in other contexts, described as the consequence of a "siloed approach" that would characterise the professionals' attitude ${ }^{22}$. Findings from this study confirm the lack of interprofessional practice even when all of the actors are in the same hospital.

The main systemic barrier identified by all of the participants was related to the consequences of deinstitutionalization. This finding is consistent with the hypothesis formulated by Kisely that "the move to care in the community may have had the unintended effect of reducing access to dental care" ${ }^{5}$. However, this study’s design does not permit confirmation of such a 
hypothesis. This issue remains nonetheless of great importance in a context of intense discussions about how long term psychiatric care should be organised in the future ${ }^{31}$.

Interviewed dentists agreed about the fact that the existence of a dental service inside the hospital represents a great opportunity. They argued that they are able to provide care in such facilities that would have been impractical to achieve in a private practice. These findings are consistent with the consensus on the need for dedicated dental clinics reached through a recent Delphi technique survey involving a panel of French dentists committed to special care dentistry ${ }^{32}$.

Education and professional training have been previously identified as major enablers for enhancing access to care for people in need for specific oral care ${ }^{33}$. That the participants did not necessarily agree on the importance of education should not in our view put its importance into question. Findings on the perception of training and education might cast more light on the actual situation of the dentists working in psychiatry in France than on the opportunities that education may create if it was implemented.

Data collection appeared to be problematic at first given the absence of systematic data on the existence of dental clinics within psychiatric hospitals in France and the overall diversity of psychiatric care delivery ${ }^{25}$. However, once the dentists were identified and contacted, they showed great interest for the study and were enthusiastic to participate. This could indicate that actors in the field acknowledge the need for research in this area. Although the findings from this study can’t be generalised for all psychiatric hospital-based dental care delivery, it highlights for the first time the barriers that are faced in this specific situation.

\section{Conclusion}

The findings of this study on dentists' perspectives help to identify a diversity of remaining barriers to oral health care in psychiatric hospitals with on-site dental clinics, especially on the organizational (the lack of interprofessional relationship) and the systemic aspects (deinstitutionalization-related risks). Consequently, they offer insights into the conditions in which such facilities could be usefully introduced. The question of whether or not this kind of dental service inside the psychiatric hospital should be implemented remains a practical and real question for stakeholders and managers; findings from this study claim for its 
development. Further research should be conducted to consider the perspectives of other actors within the psychiatric institution, including patients and medical staff members.

\section{Acknowledgement}

The researchers express their gratitude to the participants for giving their time to be interviewed. 


\section{References}

1. Kisely S, Baghaie H, Lalloo R, Siskind D, Johnson NW. A Systematic Review and Meta-Analysis of the Association Between Poor Oral Health and Severe Mental Illness. Psychosom Med. 2015;77:83-92.

2. Kisely S, Quek L-H, Pais J, Lalloo R, Johnson NW, Lawrence D. Advanced dental disease in people with severe mental illness: systematic review and meta-analysis. $\mathrm{Br} J$ Psychiatry. 2011;199:187-193.

3. Matevosyan NR. Oral Health of Adults with Serious Mental Illnesses: A Review. Community Ment Health J. 2010;46:553-562.

4. Moore S, Shiers D, Daly B, Mitchell AJ, Gaughran F. Promoting physical health for people with schizophrenia by reducing disparities in medical and dental care. Acta Psychiatr Scand. 2015;132:109-121.

5. Kisely S. No Mental Health without Oral Health. Can J Psychiatry. 2016;61:277-282.

6. Jamieson LM. The mouth as a site of structural inequalities; an introduction. Community Dent Health. 2016;33:151-151.

7. Corridore D, Guerra F, Marra CL, Thiene DD, Ottolenghi L. Oral Health Status and Oral Health-Related Quality of Life in Italian Deinstitutionalized Psychiatric Patients. Clin Ter. 2017;168:77-83.

8. Denis F, Milleret G, Wallenhorst T, Carpentier M, Rude N, Trojak B. Oral health in schizophrenia patients: A French Multicenter Cross-Sectional Study. Presse Médicale. 2019;48:89-99.

9. Ashour AA, Basha S, Enan ET, Basalem A, Qahatani AA. Association between obesity/overweight and dental caries in psychiatric patients. Ann Saudi Med. 2019;39:178-184.

10. Bertaud-Gounot V, Kovess-Masfety V, Perrus C, Trohel G, Richard F. Oral health status and treatment needs among psychiatric inpatients in Rennes, France: a cross-sectional study. BMC Psychiatry. 2013;13:227-235.

11. Chu K-Y, Yang N-P, Chou P, Chiu H-J, Chi L-Y. Factors associated with dental caries among institutionalized residents with schizophrenia in Taiwan: a cross-sectional study. BMC Public Health. 2010;10:482-487.

12. Djordjevic V, Jovanovic M, Milicic B, Stefanovic V, Djukic-Dejanovic S. Prevalence of dental caries in hospitalized patients with schizophrenia. Vojnosanit Pregl. 2016;73:1102-1108.

13. Gurbuz O, Alatas G, Kurt E, Issever H, Dogan F. Oral health and treatment needs of institutionalized chronic psychiatric patients in Istanbul, Turkey. Community Dent Health. 2010;27:151-157.

14. Lewis S, Jagger RG, Treasure E. The oral health of psychiatric in-patients in South Wales. Spec Care Dentist. 2001;21:182-186. 
15. Nikfarjam M, Parvin N. Oral Health Status in Three Long Term Care Units of Schizophrenic Patients in Chaharmahal-Bakhtiari Province, Iran. Iran Red Crescent Med J. 2013;15:371-372.

16. Teng P-R, Su J-M, Chang W-H, Lai T-J. Oral health of psychiatric inpatients: a survey of central Taiwan hospitals. Gen Hosp Psychiatry. 2011;33:253-259.

17. Velasco E, Machuca G, Martinez-Sahuquillo A, Rios V, Lacalle J, BulloAn P. Dental health among institutionalized psychiatric patients in Spain. Spec Care Dentist. 1997;17:203-206.

18. Zusman SP, Ponizovsky AM, Dekel D, et al. An assessment of the dental health of chronic institutionalized patients with psychiatric disease in Israel. Spec Care Dentist. 2010;30:18-22.

19. Chu K-Y, Yang N-P, Chou P, Chiu H-J, Chi L-Y. Comparison of oral health between inpatients with schizophrenia and disabled people or the general population. J Formos Med Assoc. 2012;111:214-219.

20. Ponizovsky AM, Zusman SP, Dekel D, et al. Effect of Implementing Dental Services in Israeli Psychiatric Hospitals on the Oral and Dental Health of Inpatients. Psych Serv. 2009;60:799-803.

21. Stevens T, Spoors J, Hale R, Bembridge H. Perceived oral health needs in psychiatric inpatients: impact of a dedicated dental clinic. The Psychiatrist. 2010;34:518-521.

22. Slack-Smith L, Hearn L, Scrine C, Durey A. Barriers and enablers for oral health care for people affected by mental health disorders. Aust Dent J. 2017;62:6-13.

23. Scrine C, Durey A, Slack-Smith L. Providing oral care for adults with mental health disorders: Dental professionals' perceptions and experiences in Perth, Western Australia. Community Dent Oral Epidemiol. 2019;47:78-84.

24. Scrine C, Durey A, Slack-Smith L. Enhancing oral health for better mental health: Exploring the views of mental health professionals. Int J Ment Health Nurs. 2018;27:178-186.

25. Coldefy M. The Evolution of Psychiatric Care Systems in Germany, England, France and Italy: Similarities and Differences. Quest Eco San. 2012;180:1-8.

26. Verdoux H, Tignol J. Focus on psychiatry in France. Br J Psychiatry. 2003;183:466-471.

27. Taylor Salisbury T, Killaspy H, King M. An international comparison of the deinstitutionalisation of mental health care: Development and findings of the Mental Health Services Deinstitutionalisation Measure (MENDit). BMC Psychiatry. 2016;16:54.

28. Stewart K, Gill P, Chadwick B, Treasure E. Qualitative research in dentistry. Br Dent J. 2008;204:235-239.

29. Hsieh H-F, Shannon SE. Three Approaches to Qualitative Content Analysis. Qual Health Res. 2005;15:1277-1288. 
30. Friedlander AH, Brill NQ. The dental management of patients with schizophrenia. Spec Care Dentist. 1986;6:217-218.

31. Sisti DA, Segal AG, Emanuel EJ. Improving Long-term Psychiatric Care: Bring Back the Asylum. JAMA. 2015;313:243-244.

32. Blaizot A, Catteau C, Delfosse C, Hamel O, Trentesaux T. Obstacles to comprehensive dental care in patients with sustained limitations of their decision-making abilities: findings from a Delphi study. Eur J Oral Sci. 2018;126:222-233.

33. Subar P. Pre- and Postdoctoral Dental Education Compared to Practice Patterns in Special Care Dentistry. J Dent Educ. 2012;76:1623-1628. 
Table 1 Description of the sample

\begin{tabular}{|c|c|c|c|c|}
\hline Interview & Sex & Age & Lenght (min) & Type of practice \\
\hline 1 & M & $50 / 60$ & 25 & Combined (hospital and private practice) \\
\hline 2 & M & $50 / 60$ & 65 & Hospital \\
\hline 3 & M & $60 / 70$ & 41 & Combined (hospital and private practice) \\
\hline 4 & M & $50 / 60$ & 63 & Hospital \\
\hline 5 & $\mathrm{~F}$ & $60 / 70$ & 57 & Hospital \\
\hline 6 & M & $50 / 60$ & 25 & Combined (hospital and private practice) \\
\hline 7 & M & $50 / 60$ & 69 & Combined (hospital and private practice) \\
\hline 8 & $\mathrm{~F}$ & $50 / 60$ & 89 & Combined (hospital and private practice) \\
\hline
\end{tabular}

